DOI: $10.2478 /$ lpts-2019-0005

\title{
INVESTIGATION OF THE INFLUENCE OF HIGH FREQUENCY ELECTROMAGNETIC FIELDS ON SORPTION PROCESSES
}

\author{
A. D. Galimbekov ${ }^{1}$, M. A. Kadyrov ${ }^{2}$, D. A. Drugov ${ }^{3}$, \\ G. I. Muratova ${ }^{4}$, M. A. Baizharikova ${ }^{5}$ \\ ${ }^{1}$ Department of Heat Power Engineering and Physics, \\ Bashkir State Agrarian University, \\ 450001, 34 50th Anniversary of October Str., Ufa, Republic of Bashkortostan, \\ RUSSIA \\ airbek@yandex.ru \\ ${ }^{2,3}$ Department of Geology of Oil and Gas Fields, \\ Tyumen Industrial University \\ 625000, 56 Volodarskiy Str., Tyumen, RUSSIA \\ kadyrov-marse1@bk.ru \\ den.sub2016@yandex.ru \\ ${ }^{4}$ Faculty of Information Technology, Automatic and Telecommunications, \\ Taraz State University named after M.Kh. Dulaty \\ 010000, 60 Tole-bi Str., Taraz, KAZAKHSTAN \\ gaukhar70@mail.ru \\ ${ }^{5}$ Department of Applied Informatics and Programming, \\ Taraz State University named after M.Kh. Dulaty \\ 010000, 60 Tole-bi Str., Taraz, KAZAKHSTAN \\ marina.2288@mail.ru
}

The present paper studies the effect of high frequency electromagnetic fields on sorption processes. The equation of sorption kinetics describes the main mechanisms of the above effect. This can serve as the basis for more effective high frequency electromagnetic field technology to increase oil recovery by reducing adsorption of oil components on the porous bed skeleton.

Keywords: adsorption, high frequency electromagnetic field, porous structure

\section{INTRODUCTION}

It is known that adsorption layers of polar oil components are formed on the porous channel surfaces at oil filtration in a porous medium. These layers change the 
molecular nature of solid surface and serve as a basis to form oil boundary layers whose viscosity exceeds that of oil in the bulk by an order of magnitude and whose thickness is commensurable with porous channel radius in a number of cases. Due to deposition of oil adsorption layers, the cross-section of filtration channels of porous medium is reduced, its penetrability decreases and, as a result, oil recovery of the porous bed drops [1], [2].

One of the promising technologies used to extract film oil adsorbed in the bed is based on application of high frequency electromagnetic fields (HF EMF). However, the mechanisms of HF EMF action on sorption processes still remain little studied. That is why theoretical studies in this area are very topical.

The objective of the present study is the theoretical investigation of the effect of HF EMF on sorption processes.

\section{THE FEATURES OF FILTRATION OF A MONOPHASE SINGLE- COMPONENT SYSTEM IN POROUS MEDIUM}

Let us consider filtration of a monophase single-component system in a porous medium at HF EMF action (with allowance made for sorption processes) within the framework of the "impurity" theory presented in [3]-[6]. It is assumed that the system contains a solute (impurity). Impurity absorption by the porous medium skeleton will be named sorption, bearing in mind impurity adsorption on the skeleton surface. The impurity mass concentration will be denoted by $c_{i m p}$; the mass concentration of adsorbate (part of impurities sorbed on the pore surface) will be denoted by $a$.

We take the system as a solution whose density is a sum of the solvent and impurity densities:

$$
\rho=\rho_{s}+\rho_{\text {imp }}=\rho\left(c_{s}+c_{i m p}\right) \text {. }
$$

Here $\rho_{s}, c_{s}, \rho_{i m p}$ and $c_{i m p}$ are the densities and mass concentrations of solvent and impurity (dissolved in solution), respectively; $\rho$ is the total medium density. HF EMF acting on the considered system is

$$
\vec{E}=\vec{E}_{0}(\vec{r}) \exp (i \omega t), \quad \vec{H}=\vec{H}_{0}(\vec{r}) \exp (i \omega t)
$$

Here $\vec{E}_{0}(\vec{r})$ and $\vec{H}_{0}(\vec{r})$ are amplitudes of the electric and magnetic field strengths, respectively; $\omega$ is the HF EMF angular frequency; $i$ is the imaginary unit; $\vec{r}$ is the radius vector of material continuum point.

Let us assume that the system under investigation is a nonmagnetic dielectric with low conductivity. The considered problem deals with the materials of oil technology, so the corresponding equations of state are as follows: 


$$
\begin{aligned}
& \vec{D}=\varepsilon_{0} \varepsilon_{e f} \vec{E}, \quad \vec{B}=\mu_{0} \vec{H}, \\
& \varepsilon_{e f}=(1-m) \varepsilon_{s k}+m \varepsilon \\
& \varepsilon=\varepsilon^{\prime}\left(\omega, c_{s}, c_{i m p}, a, \rho, T\right)-i \varepsilon^{\prime \prime}\left(\omega, c_{s}, c_{i m p}, a, \rho, T\right) .
\end{aligned}
$$

Here $\vec{D}$ and $\vec{B}$ are vectors of electric and magnetic induction, respectively; $\varepsilon_{0}$ and $\mu_{0}$ are the electric and magnetic constants, respectively; $\varepsilon_{e f}$ is the medium dielectric permittivity; $m$ and $\varepsilon_{s k}$ are skeleton porosity and dielectric permittivity, respectively; $\varepsilon$ is dielectric permittivity of solvent with impurity; $\varepsilon^{\prime}$ and $\varepsilon^{\prime \prime}$ are the real and imaginary parts of the above dielectric permittivity.

\section{ANALYSIS OF THE HENRY ADSORPTION}

Let us obtain the sorption kinetics equation. In this case, the Henry adsorption will be considered, so we have to determine equilibrium conditions for the impurity in solution and part of impurity adsorbed on the pore surface. Based on thermodynamics of irreversible processes, the effect of HF EMF on chemical reactions in multicomponent media was studied and the Guldberg-Waage equation generalized to the case of HF EMF action was obtained in [7]-[9]. Considering adsorption as a variety of chemical reaction, (according to [7]-[9]) the GuldbergWaage mass action equation may be presented as follows:

$$
\begin{aligned}
& \frac{N_{a d}}{N_{0}}=K^{*}, \\
& K^{*}=K_{0} \exp \left(-\frac{E_{A}^{\prime}-E_{A}^{\prime \prime}}{R T}\right), \\
& E_{A}^{\prime}=E_{A m}^{\prime}+\frac{\varepsilon_{0} E_{0}^{2} M}{4 \rho}\left(\left.\frac{\partial}{\partial a}\left(\varepsilon^{\prime}-\omega \frac{\partial \varepsilon^{\prime}}{\partial \omega}\right)\right|_{\xi=\xi_{0}}\right), \\
& E_{A}^{\prime \prime}=E_{A m}^{\prime \prime}+\frac{\varepsilon_{0} E_{0}^{2} M}{4 \rho}\left(\left.\frac{\partial}{\partial c_{i m p}}\left(\varepsilon^{\prime}-\omega \frac{\partial \varepsilon^{\prime}}{\partial \omega}\right)\right|_{\xi=\xi_{0}}\right) .
\end{aligned}
$$

Here $N_{a d}=\frac{n_{a d}}{n_{0}+n_{a d}}$ is the mole fraction of adsorbate; $n_{a d}=\frac{m_{a d}}{M}=\frac{1}{M} \int_{V} \rho a d V$ is the number of adsorbate moles in a selected medium volume; $n_{0}=\frac{m_{o}}{M}=\frac{1}{M} \int_{V} \rho m c_{i m p 0} d V$ 
is an equilibrium number of impurity moles in solution in the selected medium volume; $N_{0}=\frac{n_{0}}{n_{0}+n_{a d}}$ is an equilibrium mole fraction of impurity solved in solution; $c_{i m p 0}$ is an equilibrium mass concentration of impurity in solution; $M$ is impurity mole mass; $E_{A}^{\prime}$ is activation energy of direct chemical reaction at HF EMF action (adsorption); $E_{A}^{\prime \prime}$ is activation energy of back chemical reaction at HF EMF action desorption; $K^{*}$ is the adsorption equilibrium constant.

Therefore, Eq. (6) can be rewritten as follows:

$\frac{a}{m c_{i m p 0}}=K^{*}$

from which

$c_{i m p 0}=\frac{a}{K^{*} m}=\frac{a}{\gamma}=\frac{a}{\gamma_{0}} \exp \left(-\frac{Q}{R}\left(\frac{1}{T}-\frac{1}{T_{0}}\right)\right)$

or

$a=\gamma c_{i m p ~}=\gamma_{0} \exp \left(\frac{Q}{R}\left(\frac{1}{T}-\frac{1}{T_{0}}\right)\right) c_{i m p 0}$.

Equation (11) is the Henry law generalized to the case of HF EMF action; $\gamma$ is the Henry coefficient equal to

$$
\gamma=K^{*} m=K_{0} m \exp \left(-\frac{E_{A}^{\prime}-E_{A}^{\prime \prime}}{R T}\right)=K_{0} m \exp \left(-\frac{Q}{R T}\right)=\gamma_{0} \exp \left(\frac{Q}{R}\left(\frac{1}{T}-\frac{1}{T_{0}}\right)\right) .
$$

Here $\gamma_{0}=K_{0} m \exp \left(\frac{Q}{R T_{0}}\right)$ is the Henry constant value at $T=T_{0}$; $Q=Q_{m}+Q^{e m}$ is the adsorption heat; $Q_{m}=E_{A m}^{\prime \prime}-E_{A m}^{\prime}>0$ is adsorption heat without regard for HF EMF action; $Q^{e m}=\frac{\varepsilon_{0} E_{0}^{2} M}{4 \rho}\left(\left.\frac{\partial}{\partial c_{i m p}}\left(\varepsilon^{\prime}-\omega \frac{\partial \varepsilon^{\prime}}{\partial \omega}\right)\right|_{\xi=\xi_{0}}-\left.\frac{\partial}{\partial a}\left(\varepsilon^{\prime}-\omega \frac{\partial \varepsilon^{\prime}}{\partial \omega}\right)\right|_{\xi=\xi_{0}}\right)$ is adsorption heat due to HF EMF action.

On the other hand, the rate of adsorbate mass variation in the selected volume of a porous medium is proportional to the difference $\left(m \rho c_{i m p}-m \rho c_{i m p ~} 0\right)$ : 


$$
\frac{\partial}{\partial t} \int_{V} \rho a d V=\beta \int_{V}\left(m \rho c_{i m p}-m \rho c_{i m p 0}\right) d V,
$$

where $\beta=\beta_{m}+\beta^{e m}$ is the adsorption rate; $\beta_{m}$ is the adsorption rate independent of HF EMF; $\beta^{e m}$ is the adsorption rate dependent on HF EMF.

Thus, after some transformations, we get the sorption kinetics equation:

$$
\frac{\partial \rho a}{\partial t}=m \rho\left(\beta_{m}+\beta^{e m}\right) \cdot\left(c_{i m p}-a \gamma_{0}^{-1} \exp \left(-\frac{Q_{m}+Q^{e m}}{R} \cdot\left(\frac{1}{T}-\frac{1}{T_{0}}\right)\right)\right)
$$

\section{ANALYSIS OF MECHANISMS OF HF EMF INFLUENCE ON SORPTION KINETICS}

By analysing the sorption kinetics equation (Eq. (14)), the following mechanisms of HF EMF influence on sorption kinetics can be distinguished:

1. The heat mechanism of HF EMF action: at this action, the medium is heated due to dielectric losses. As the Henry coefficient (Eq. (12)) depends on temperature, this results in displacement of the adsorption equilibrium curve [10]-[13]. The Henry coefficient decreases as temperature grows; so the desorption processes prevail. One can exert control over intensity of medium heating by choosing HF EMF frequency.

2. The HF EMF influence on sorption kinetics via adsorption heat: an additional electromagnetic component $Q^{e m}$ appears in the expression for adsorption heat at HF EMF action [14]. There are two special cases that can be implemented depending on the HF EMF frequency:

2.1. $Q^{e m}>0$; in this case, adsorption heat increases. This leads to growth of the Henry coefficient and thus to predominance of adsorption processes.

2.2. $Q^{e m}<0$; in this case, adsorption heat decreases. This leads to reduction of the Henry coefficient and thus to predominance of desorption processes.

3. The HF EMF influence on the rate of sorption processes: an electromagnetic part $\beta^{e m}$ appears in the expression for adsorption rate at HF EMF action. There are also two special cases that can be implemented depending on the HF EMF frequency:

3.1. $\beta^{e m}>0$; in this case, the adsorption rate increases and the system goes to adsorption equilibrium more quickly.

3.2. $\beta^{e m}<0$; in this case, the adsorption rate decreases and the system goes to adsorption equilibrium more slowly.

\section{CONCLUSION}

A theoretical study of the effect of HF EMF on sorption processes has been carried out. It has been established that one can exert control over adsorption- 
desorption processes by selectively choosing HF EMF power and frequency. The mechanisms of HF EMF action on sorption processes (the heat mechanism of HF EMF action, the HF EMF influence on sorption kinetics via adsorption heat, the HF EMF influence on the rate of sorption processes) considered in the present paper can form the basis of more efficient HF EMF technologies to increase oil recovery of porous beds by decreasing adsorption of oil components on the rock skeleton.

\section{REFERENCES}

1. Formalev, V.F., Kolesnik, S.A., \& Kuznetsova, E.L. (2018). On the wave heat transfer at times comparable with the relaxation time upon intensive convective-conductive heating. High Temperature, 56(3), 393-397.

2. Kolesnik, S.A., Formalev, V.F., \& Kuznetsova, E.L. (2015). On inverse boundary thermal conductivity problem of recovery of heat fluxes to the boundaries of anisotropic bodies. High Temperature, 53(1), 68-72.

3. Barenblatt, G.I., Entov, V.M., \& Ryzhik, V.M. (1984). Movement of liquids and gases in natural formations. Moscow: Nedra.

4. Nikolaevsky, V.N. (1984). Mechanics of porous and fissured media. Moscow: Nedra.

5. Bondarev, E.A., \& Nikolaevsky, V.N. (1962). Convective diffusion in porous media taking into account the adsorption phenomenon. Applied Mechanics and Technical Physics, 5, 128-134.

6. Tlebayev, M.B., Tazhiyeva, R.N., Doumcharieva, Zh.E., Aitbayeva, Z.K., \& Baijarikova, M.A. (2017). Mathematical research of the accelerated three-stage process of substrate fermentation in bioreactors. Journal of Pharmaceutical Sciences and Research, 9(4), 392-400.

7. Galimbekov, A.D. (2004). Influence of high-frequency electromagnetic field on chemical reactions in multicomponent media. Journal of Physical Chemistry, 78(9), 1693-1697.

8. Galimbekov, A.D. (2007). Some aspects of the interaction of electromagnetic fields with polarizing media. Thesis for the degree of Doctor of Physics and Mathematics. Ufa: Bashkir State University.

9. Kovaleva, L.A., \& Galimbekov, A.D. (2004). Influence of a high-frequency electromagnetic field on physicochemical processes in multicomponent media. Bulletin of the Orenburg State University, 1(26), 141-146.

10. Coello-Fiallos, D.C., Espin-Lagos, S.M., Vacacela Gomez, C., Tavolaro, A., \& Caputi, L.S. (2018). Comparison of pure membranes of $13 X$ and 5A zeolite for removal of acridine orange dye from aqueous solutions. Periódico Tchê Química, 15(29), 251-257.

11. Cavallari, R.V., De Lima, N.B., Silva, J.C.M., Bergamashi, V.S., \& Ferreira, J.C. (2018). Preparation of catalyst support from bio carbon. Periódico Tchê Química, 15(30), 115122.

12. Vian, A., Davies, E., Gendraud, M., \& Bonnet, P. (2016). Plant responses to high frequency electromagnetic fields. Biomed Res Int., 2016, 1830262.

13. D’Agostino, S., Monica, C.D., Palizzi, E., Di Pietrantonio, F., Benetti, M., Cannatà, D., ... Ramundo-Orlando, A. (2018). Extremely high frequency electromagnetic fields facilitate electrical signal propagation by increasing transmembrane potassium efflux in an artificial axon model. Scientific Reports, 8, 9299.

14. Kivrak, E.G., Yurt, K.K., Kaplan, A.A., Alkan, I., \& Altun, G. (2017). Effects of electromagnetic fields exposure on the antioxidant defense system. Journal of Microscopy and Ultrastructure, 5(4), 167-176. 
AUGSTFREKVENCES ELEKTROMAGNĒTISKO LAUKU IETEKMES IZPĒTE UZ SORBCIJAS PROCESIEM

\author{
A. D. Galimbekovs, M. A. Kadirovs, D. A. Drugovs, \\ G. I. Muratova, M. A. Baižarikova
}

Kopsavilkums

Šajā rakstā apskatīta augstfrekvences elektromagnētisko lauku ietekme uz sorbcijas procesiem. Sorbcijas kinētikas vienādojums apraksta galvenos minētā efekta mehānismus. Tas var kalpot par pamatu efektīvākai augstfrekvences elektromagnētiskā lauka tehnologijiai, lai palielinātu elılas atgūšanu, samazinot eḷıas komponentu adsorbciju porainā gultnes skeletā.

12.11.2018. 